\title{
Coronary lesions in patients with COPD (Global Initiative for Obstructive Lung Disease stages I-III) and suspected or confirmed coronary arterial disease
}

This article was published in the following Dove Press journal: International Journal of COPD

\author{
Igor Larchert Mota' \\ Antônio Carlos Sobral \\ Sousa ${ }^{1-3}$ \\ Maria Luiza Doria \\ Almeida ${ }^{1,2}$ \\ Enaldo Vieira de Melo² \\ Eduardo José Pereira \\ Ferreira ${ }^{2,3}$ \\ José Barreto Neto ${ }^{2}$ \\ Carlos José Oliveira \\ Matos 1,3 \\ Caio José Coutinho Leal \\ Telino ${ }^{2,3}$ \\ Maria Júlia Silveira Souto ${ }^{2,3}$ \\ Joselina Luzia Menezes \\ Oliveira ${ }^{1-3}$ \\ 'Department of Internal Medicine, \\ Pneumology Division, Federal \\ University of Sergipe (FUS), \\ São Cristóvão, Sergipe, Brazil; \\ ${ }^{2}$ Department of Internal Medicine, \\ Cardiology Division, Federal \\ University of Sergipe (FUS), \\ São Cristóvão, Sergipe, Brazil; \\ ${ }^{3}$ Echocardiography Laboratory \\ (ECOLAB), Clínica e Hospital São \\ Lucas, Aracaju, Sergipe, Brazil
}

Correspondence: Igor Larchert Mota Federal University of Sergipe, Avenida Marechal Rondon, s/n - Jardim Rosa Elze, São Cristóvão, Sergipe, 49100-000, Brazil Email igorlarchert@hotmail.com
Background: Systemic inflammation is the pathophysiological link between coronary artery disease (CAD) and COPD. However, the influence of subclinical COPD on patients with suspected or diagnosed CAD is largely unknown. Thus, this study was designed to evaluate the degree of coronary involvement in patients with COPD and suspected or confirmed CAD.

Methods: In this cross-sectional study, carried out between March 2015 and June 2017, 210 outpatients with suspected or confirmed CAD were examined by both spirometry and coronary angiography or multidetector computed tomography. These patients were divided into two groups: with and without COPD. Size, site, extent, and calcification of the coronary lesions, and the severity of COPD were analyzed.

Results: COPD patients $(\mathrm{n}=101)$ presented with a higher frequency of obstructive coronary lesions $\geq 50 \%(\mathrm{n}=72,71.3 \%)$, multivessels $(\mathrm{n}=29,28.7 \%)$, more lesions of the left coronary trunk $(\mathrm{n}=18,17.8 \%)$, and more calcified atherosclerotic plaques and higher Agatston coronary calcium score than the patients without $\operatorname{COPD}(P<0.0001)$. The more severe the COPD in the Global Initiative for Obstructive Lung Disease stages, the more severe the CAD and the more calcified coronary plaques $(P<0.0001)$. However, there was no difference between the two groups with respect to the main risk factors for CAD. In the univariate analysis, COPD was an independent predictor of obstructive CAD (odds ratio [OR] 4.78; 95\% confidence interval: 2.21-10.34; $P<0.001)$.

Conclusion: In patients with suspected CAD, comorbid COPD was associated with increased severity and extent of coronary lesions, calcific plaques, and elevated calcium score independent of the established risk factors for CAD. In addition, the more severe the COPD, the greater the severity of coronary lesions and calcification present.

Keywords: COPD, coronary artery disease, spirometry, coronary angiography, multidetector computed tomography

\section{Background}

COPD is the fourth leading cause of mortality globally, affecting more than 210 million people. ${ }^{1}$ At the same time, data from the World Health Organization show that 17.7 million cardiovascular disease deaths worldwide in 2015 (31\% of all-cause mortality), of whom 7.4 million were due to coronary artery disease (CAD). ${ }^{2}$

Evidence suggests that COPD and CAD occur in overlapping populations, possibly due to the common risk factors. ${ }^{3-7}$ Patients with comorbid CAD and COPD suffer longer 
hospital stays, higher healthcare costs, lower quality of life, and functional status than patients with only one of these diseases. $^{4-9}$

Systemic inflammation, because it plays a central role in the pathogenesis of atherosclerosis and COPD, could be a pathophysiological link between them. ${ }^{7}$ This association persists after control of cardiovascular risk factors and is stronger than the correlations between individuals who never smoked and smokers without diagnosed COPD. ${ }^{9}$ However, there is still no consensus in the literature because COPD was considered to be a predictor of CAD and increased cardiovascular risk in some studies, ${ }^{10,11}$ whereas other studies did not. ${ }^{12}$

Although some large population-based studies have linked airflow limitation (AL) with coronary disease severity, ${ }^{10-13}$ the effects of COPD on the extent and severity of coronary lesions in the early stages of this disease are still largely unknown and the impact of the Global Initiative for Obstructive Lung Disease (GOLD) stages on the severity of CAD is poorly understood. ${ }^{10}$ Therefore, considering that both diseases present with inflammation as their pathophysiological substrate, this study aims to test the hypothesis as to whether COPD patients will have more advanced and severe CAD compared to the group without COPD. Thus, this study was designed to evaluate the degree of coronary involvement in patients with COPD and suspected or confirmed CAD.

\section{Methods}

\section{Study design and population}

This cross-sectional and analytical study, carried out from March 2015 to June 2017, used a cohort of 552 outpatients, referred by their attending physicians for transthoracic echocardiography, exercise stress test, or exercise echocardiography (EE) for the diagnosis of myocardial ischemia. The investigation was carried out in the cardiology laboratories of the University Hospital of the Federal University of Sergipe (FUS), in addition to the Echocardiography Laboratory (ECOLAB) of the Clínica e Hospital São Lucas, Aracaju, Sergipe, Brazil, a cardiology referral center, with Accreditation with Excellence (Instituto Qualisa de Gestão) and Qmentum International Diamond (Accreditation Canada). Of 552 outpatients, 233 were selected based on the following inclusion criteria: patients older than 40 years (for the GOLD criteria for spirometric diagnosis of COPD), ${ }^{14}$ who were stable at least 8 weeks (ie, those who did not present respiratory infections and hospitalizations in the 8 weeks prior to data collection and did not have clinical evidence of heart failure or acute coronary syndrome, or blood pressure levels prohibitive for exercise [systolic blood pressure $\geq 230 \mathrm{mmHg}$ and/or diastolic $\geq 130 \mathrm{mmHg}]$ ), who were presented with suspected or established CAD; and who were scheduled for coronary angiography (CAG) or multidetector computed tomography (MDCT).

Based on the diagnosis of reversible obstruction with a typical history of this pathology (allergy, hyperreactivity, and onset of symptoms at an early age), patients with asthma were not eligible for this study. Also, patients with occupational lung diseases or other pulmonary pathologies (sequelae of pulmonary tuberculosis and/or pulmonary fibrosis) that could mask the diagnosis of COPD; with contraindications to MDCT such as renal insufficiency, allergy to iodine, or multiple myeloma; who weigh $>120 \mathrm{~kg}$ limitation of the tomography table, and with creatinine clearance $<50 \mathrm{~mL} / \mathrm{min}$ (because of possible nephrotoxicity of iodinated contrast) were excluded from this study. Patients were divided into COPD and non-COPD groups based on their spirometric findings. The study was approved by the Research Ethics Committee of FUS, and a signed, informed consent was obtained from all of the volunteers.

\section{Demographic and clinical characteristics}

Clinical data were collected through a structured questionnaire, which included weight, height, symptoms, medications used, risk factors for CAD, history of heart disease, and results of previous laboratory tests.

Dyslipidemia was defined as a serum total cholesterol level of $>200 \mathrm{mg} / \mathrm{dL}$ (after a 12-hour fast), a serum triglyceride level of $>150 \mathrm{mg} / \mathrm{dL}$ (after a 12-hour fast), or use of an antihyperlipidemia agent (statin or fibrate). ${ }^{15}$ Hypertension was considered to be present if the blood pressure levels (in three sequential measurements at 1-minute interval) were $\geq 140 / 90 \mathrm{mmHg}$ or if the patient had been prescribed antihypertensive medications. ${ }^{16}$

Diabetes mellitus (DM) was defined by the presence of fasting glycemia $>126 \mathrm{mg} / \mathrm{dL}$ or by the use of insulin and/or oral hypoglycemic agents. ${ }^{17} \mathrm{~A}$ family history of premature CAD was defined as the occurrence of clinical CAD in any first-degree relative before age 55 years in men and 65 years in women. As for smoking, the following definitions were adopted: an active smoker was someone who smoked on a daily basis at the time of the interview; an ex-smoker was any individual who, despite prior tobacco use, had not smoked in the last 6 months; and a nonsmoker was an individual who had never smoked. In addition, the history of tobacco consumption was scored considering the exposure time and packs per year. Additionally, the volunteers had no clinical 
evidence of heart failure or significant ventricular dysfunction on transthoracic echocardiography.

\section{Procedures}

Patients underwent an initial clinical investigation (medical history and physical examination) followed by a 12-lead electrocardiogram (ECG) and echocardiography, ergometric test, and/or EE. The decision to perform CAG or the MDCT was made by the attending physician according to the standard clinical practice. The variables chosen for the analysis of CAD using both CAG and MDCT were presence or absence of CAD and degree of stenosis $(<50 \%$, nonobstructive; $\geq 50 \%$, in at least one segment, obstructive). Classification was based on the presence of luminal obstructions in the left main coronary artery, left anterior descending artery (LAD), left circumflex artery (LCx), and right coronary artery (RCA). They were divided into univessel, bivessel, trivessel, and multivessel patterns, and the severity of the lesions was graded according to the obstructive patterns (discrete lesions of $\leq 39 \%$, moderate lesions of $40 \%$ to $69 \%$, and severe lesions of $\geq 70 \%$ in at least one affected artery). Patients undergoing cardiac evaluation were then directed to spirometry and COPD assessment.

Pre- and postbronchodilator spirometry was performed by a pulmonologist according to the American Thoracic Society criteria. ${ }^{18} \mathrm{AL}$ was defined as an FEV1/FVC ratio $<70 \%$ after the use of a bronchodilator (salbutamol, $400 \mu \mathrm{g}$ ) using a Microloop model MK8 spirometer using the Pereira ${ }^{19}$ standards developed for the Brazilian population. The evaluation followed the recommendations of the GOLD ${ }^{14}$ criteria for classifying the spirometric severity (I, II, III, and IV) of COPD, the risk of exacerbations, and the application of standard clinical evaluations for signs and symptoms (such as the modified Medical Research Council [mMRC]). The patients in this sample did not have participated in previous spirometry studies and had not been diagnosed with COPD. During the data collection phase, the principal investigator did not have the access to the pulmonary function test results and cardiology evaluations.

\section{CAG}

Angiography was performed in 106 patients, within 6 months after the EE result. The Judkins technique was used, preferably via the right radial access pathway. ${ }^{20}$ The angiographic analysis of the lesions was done by an interventional cardiologist using visual evaluation of stenotic severity in at least two orthogonal projections. All of the major epicardial vessels (left main, LAD, LCX, and RCA) and respective branches with diameters $>2.0 \mathrm{~mm}$ were evaluated. The degree of stenosis was determined as the percentage reduction of the diameter, from 0 to 100 , estimated from the reference diameter of the vessel considered normal and more proximal to the lesion. The angiograms were analyzed using a quantitative score system as recommended by the Guidelines for Coronary Angiography. ${ }^{21}$

\section{MDCT}

For the acquisition of MDCT for evaluation of the coronary arteries, a two-phase protocol was used. Initially, the Agatston coronary artery calcium score (CACS) was quantified by analyzing the regions in the coronary arteries with densities $>130$ Hounsfield Units (HU) in three adjacent pixels $\left(>1 \mathrm{~mm}^{2}\right)$. The CACS of each plate was obtained by the product of the calcification area by a factor $\mathrm{c}$ dependent on the attenuation in HU. The total CACS was calculated by summing the individual scores of each region, as described by Agatston et $\mathrm{al}^{22}$ using electron beam tomography and validated by other authors for the acquisition with multiple detector techniques. ${ }^{23}$ Following the acquisition of the noncontrast CACS with the coupled ECG, contrast media were utilized for the MDCT. ${ }^{22}$ In cases where patients had heart rates $>65 \mathrm{bpm}, 25-100 \mathrm{mg}$ of atenolol was given. The nonionic iodinated contrast agent used was iopamidol, which was injected intravenously $(\sim 1.5 \mathrm{~mL} / \mathrm{kg}$ at a concentration of $370 \mathrm{mg} / \mathrm{mL}$ at $4.5 \mathrm{~mL} / \mathrm{s}$ ). The resulting images were sent to a workstation for analysis by an experienced observer. Patients who presented with atherosclerotic plaque on MDCT were diagnosed with CAD. The classification of EC used was that of Azevedo et $\mathrm{al}^{24}$ using the degree of calcification to estimate vascular involvement (0, absent; 1-10, minimal; 11-100, mild; 101-400, moderate; 401-1,000, severe; and >1,000, very severe disease).

\section{Statistical analysis}

Quantitative variables were described by the mean and standard deviation. The Kolmogorov-Smirnov test was applied to evaluate the normality of distribution. Then, the Student's $t$-test or the Mann-Whitney test was used for independent groups, according to the normality of the sample. As for categorical variables, absolute frequency and percentage were determined. To compare the characteristics of the categorical variables between the two groups, a chi-square test or Fisher's exact test was used as appropriate. The association between the occurrence of COPD and the classic risk factors for CAD (age, gender, hypertension, DM, dyslipidemia, family history 
of CAD, body mass index [BMI], and sedentary lifestyle) and the presence of CAD were assessed by logistic regression to determine the chance (odds ratio [OR]) adjusted and not adjusted. For inclusion in the model, crude ORs with $P<0.30$ were considered and, for the model, $P<0.05$. The Statistical Package for the Social Sciences, version 21 (IBM Corporation, Armonk, NY, USA) was used to perform the necessary calculations. A $P<0.05$ on a two-tailed comparison was considered as significant for all tests.

\section{Results}

A total of 233 patients of both genders were selected in the 27-month period. After application of the exclusion criteria, 23 patients who had only CACS were dropped from the group, leaving 210 individuals for the final analysis. Of the total sample, 101 (48\%) individuals had a diagnosis of COPD, of whom 41 (19.5\%) had mild or GOLD I disease; $47(22.4 \%)$ had moderate GOLD II; and 13 (6.2\%) had severe GOLD III COPD. However, none of the patients had very serious disease (GOLD IV). Also, 138 of the patients $(65.7 \%$ [95\% CI: 59.5\%-71.9\%]) presented with CAD.
The study participants had an average age of $60 \pm 9.4$ years (range, 40-90), and 55.2\% were male. Among the comorbidities, there was a high frequency of hypertension (79\%) and dyslipidemia (68\%), and the mean BMI was $27.69 \pm 4.8 \mathrm{~kg} / \mathrm{m}^{2}$ (Table 1 ).

The demographic and clinical characteristics of the participants in the presence or absence of pulmonary involvement are shown in Table 1. Patients with COPD were older than those without it (61.2 \pm 9.86 vs $58.1 \pm 8.74$ years, $P=0.014)$, and those in the latter group had a higher likelihood of having a family history of CAD (71.6\% vs 50.5\%). Not surprisingly, they also had a lower proportion $(P<0.0001)$ of ex-smokers than those with COPD (30.3\% vs 66.3\%). However, there was no difference between the two groups with respect to gender, BMI, hypertension, DM, dyslipidemia, statin use, alcoholism, sedentary lifestyle, or angina (Table 1).

Table 2 shows the presence, extent, and severity of CAD (by the CAG or the MDCT) in the two groups of patients (with and without COPD) and the GOLD severity stages. Considering only the angiotomographic characteristics of the sample $(n=104)$, the comparison between the COPD

Table I Demographic and clinical characteristics of patients $(n=210)$ with or without COPD

\begin{tabular}{|c|c|c|c|c|}
\hline Variable & Total $(n=210)$ & $\operatorname{COPD}(n=101)$ & Non-COPD $(n=109)$ & $P$-value \\
\hline Age (years) ${ }^{\mathrm{a}}$ & $59.6 \pm 9.4$ & $61.2 \pm 9.8$ & $58.1 \pm 8.7$ & 0.014 \\
\hline Male, n (\%) & $116(55.2)$ & $55(54.5)$ & $61(56)$ & 0.826 \\
\hline BMI $\left(\mathrm{kg} / \mathrm{m}^{2}\right)^{\mathrm{a}}$ & $27.6 \pm 4.8$ & $27.3 \pm 5.3$ & $28.02 \pm 4.2$ & 0.297 \\
\hline \multicolumn{5}{|l|}{ Comorbidities, n (\%) } \\
\hline Hypertension & $166(79)$ & $83(82.2)$ & $83(76.1)$ & 0.283 \\
\hline Diabetes mellitus & $72(34.3)$ & $38(37.6)$ & $34(3 \mid .2)$ & 0.327 \\
\hline Dyslipidemia & $143(68)$ & $73(72.3)$ & $70(64.2)$ & 0.211 \\
\hline Statin use & $130(6 \mid .9)$ & $65(64.4)$ & $65(59.6)$ & 0.481 \\
\hline Family history of CAD & $129(6 \mid .4)$ & $5 I(50.5)$ & $78(7 I .6)$ & 0.002 \\
\hline \multicolumn{5}{|l|}{ Life habits, n (\%) } \\
\hline Alcoholism & $74(35.2)$ & $35(34.7)$ & $39(35.8)$ & 0.864 \\
\hline Sedentary lifestyle & $120(57.1)$ & $56(55.4)$ & $64(58.7)$ & 0.632 \\
\hline \multicolumn{5}{|l|}{ Smoking history } \\
\hline Current, n (\%) & $36(17.1)$ & 34 (33.7) & $2(1.8)$ & $<0.000$ I \\
\hline Ex-smoker, n (\%) & $100(47.6)$ & $67(66.3)$ & $33(30.3)$ & \\
\hline Never smoker, n (\%) & $74(35.2)$ & $0(0)$ & $74(67.9)$ & \\
\hline Pack-years $^{a}$ & $17.4 \pm 22.2$ & $25.6 \pm 27.7$ & $10.9 \pm 16.7$ & 0.001 \\
\hline \multicolumn{5}{|l|}{ Angina, n (\%) } \\
\hline Typical & $78(37.1)$ & $44(43.6)$ & $34(3 \mid .2)$ & 0.101 \\
\hline Atypical & $58(27.6)$ & $22(21.8)$ & $36(33)$ & \\
\hline No pain & $74(35.2)$ & $35(34.7)$ & $39(35.8)$ & \\
\hline \multicolumn{5}{|l|}{ mMRC score, n (\%) } \\
\hline 0 & $60(28.6)$ & $2(2)$ & $58(53.2)$ & $<0.000 \mathrm{I}$ \\
\hline 1 & $94(44.8)$ & $51(50.5)$ & $43(39.4)$ & \\
\hline 2 & $40(19)$ & $32(31.7)$ & $8(7.3)$ & \\
\hline 3 & $16(7.6)$ & $16(15.8)$ & $0(0)$ & \\
\hline
\end{tabular}

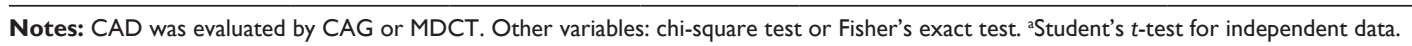

Abbreviations: BMI, body mass index; CAD, coronary artery disease; CAG, coronary angiography; MDCT, multidetector computed tomography; mMRC, modified Medical Research Council. 
Table 2 Presence, extent, and severity of CAD in patients with and without COPD, and by GOLD stages $(n=210)$

\begin{tabular}{|c|c|c|c|c|c|c|c|}
\hline Variable & $\begin{array}{l}\text { COPD } \\
(n=101)\end{array}$ & $\begin{array}{l}\text { Non-COPD } \\
(n=109)\end{array}$ & $P$-value & $\begin{array}{l}\text { GOLD I } \\
(n=4 I)\end{array}$ & $\begin{array}{l}\text { GOLD II } \\
(n=47)\end{array}$ & $\begin{array}{l}\text { GOLD III } \\
(n=13)\end{array}$ & $P$-value ${ }^{a}$ \\
\hline CAD, n (\%) & $89(88.1)$ & $49(45)$ & $<0.0001$ & $36(87.8)$ & $40(85.1)$ & $13(100)$ & $<0.0001$ \\
\hline \multicolumn{2}{|c|}{ Degree of stenosis, n (\%) } & & $<0.0001$ & & & & $<0.0001$ \\
\hline Lesion $\geq 50 \%$ & $72(7 \mathrm{I} .3)$ & $23(2 I .1)$ & & $32(78)$ & $27(57.4)$ & $13(100)$ & \\
\hline Lesion $<50 \%$ & $17(16.8)$ & $26(23.9)$ & & $4(9.8)$ & $13(27.7)$ & $0(0)$ & \\
\hline \multicolumn{2}{|c|}{ Extent of CAD, $n(\%)$} & & $<0.0001$ & & & & $<0.0001$ \\
\hline Univessel & $16(15.8)$ & $14(12.8)$ & & $5(12.2)$ & $10(21.3)$ & I (7.7) & \\
\hline Bivessel & $19(18.8)$ & $14(12.8)$ & & $10(24.4)$ & $6(12.8)$ & $3(23.1)$ & \\
\hline Trivessel & $25(24.8)$ & $12(11)$ & & $12(29.3)$ & $10(21.3)$ & $3(23.1)$ & \\
\hline Multivessel & $29(28.7)$ & $9(8.3)$ & & $9(22)$ & I4 (29.8) & $6(46.2)$ & \\
\hline LCT, n (\%) & $18(17.8)$ & $4(3.7)$ & $<0.0001$ & $6(14.6)$ & $10(21.3)$ & $2(15.4)$ & 0.06 \\
\hline \multicolumn{2}{|c|}{ Severity of CAD, $n(\%)$} & & $<0.0001$ & & & & $<0.000$ I \\
\hline Mild & $10(9.9)$ & $16(14.7)$ & & $2(4.9)$ & $8(17)$ & $0(0)$ & \\
\hline Moderate & $17(16.8)$ & $22(20.2)$ & & $6(14.6)$ & $10(21.3)$ & I (7.7) & \\
\hline Severe & $62(61.4)$ & $11(10.1)$ & & $28(68.3)$ & $22(46.8)$ & $12(92.3)$ & \\
\hline
\end{tabular}

Notes: CAD was evaluated by CAG or MDCT. aP-value referring to the comparison of the GOLD stage groups with the non-COPD group. Other variables: chi-square or Fisher's exact test.

Abbreviations: CAD, coronary artery disease; CAG, coronary angiography; GOLD, Global Initiative for Obstructive Lung Disease; LCT, left coronary trunk; MDCT, multidetector computed tomography.

and GOLD stages with the non-COPD group is visualized in Table 3 .

The adjusted logistic regression analysis identified predictors of CAD that included COPD (OR 11.42, 95\% CI: 5.30-24.59, $P<0.001$ ) and male gender (OR 3.96, 95\% CI: $1.96-7.98, P=0.001)$. However, age, hypertension, DM dyslipidemia, and family history of CAD were not the risk factors for CAD (Table 4). BMI and sedentary lifestyle, although generally considered to be risk factors for CAD, were not entered into the model because they did not present $(P<0.30)$. Table 5 shows that COPD was an independent predictor of obstructive CAD with lesions $\geq 50 \%$ of the coronary lumen (OR 4.78, 95\% CI: $2.21-10.34, P<0.001$ ).

\section{Discussion}

To the best of our knowledge, this is the first study in which patients with suspected or confirmed CAD were found to have subclinical COPD associated with a higher frequency

Table 3 Angiotomographic characteristics of patients with and without COPD, and by GOLD stages $(n=104)$

\begin{tabular}{|c|c|c|c|c|c|c|c|}
\hline Variable & $\begin{array}{l}\text { COPD } \\
(n=49)\end{array}$ & $\begin{array}{l}\text { Non-COPD } \\
(n=55)\end{array}$ & $P$-value & $\begin{array}{l}\text { GOLD I } \\
(n=12)\end{array}$ & $\begin{array}{l}\text { GOLD II } \\
(n=28)\end{array}$ & $\begin{array}{l}\text { GOLD III } \\
(n=09)\end{array}$ & $P$-value ${ }^{a}$ \\
\hline Type of coronary plate, n (\%) & & & $<0.0001$ & & & & $<0.0001$ \\
\hline Not calcified & $2(4.1)$ & $6(10.9)$ & & $39(70.9)$ & $0(0)$ & $2(7.1)$ & \\
\hline Mildly calcified & $3(6.1)$ & $4(7.3)$ & & $6(10.9)$ & I (8.3) & I (3.6) & \\
\hline Moderately calcified & II (22.4) & $5(9.1)$ & & $4(7.3)$ & $3(25)$ & $8(28.6)$ & \\
\hline Severely calcified & $24(49)$ & I (I.8) & & $5(9.1)$ & $4(33.3)$ & $13(46.4)$ & \\
\hline Mixed & I (2) & $0(0)$ & & I (I.I) & $0(0)$ & $0(0)$ & \\
\hline CACS, n (\%) & & & $<0.0001$ & & & & $<0.0001$ \\
\hline No calcification (0) & II (22.4) & $40(72.7)$ & & $40(72.7)$ & $4(33.3)$ & $7(25)$ & \\
\hline Minimum $(0-10)$ & $4(8.2)$ & $5(9.1)$ & & $5(9.1)$ & $2(16.7)$ & $2(7.1)$ & \\
\hline Mild (II-I00) & II (22.4) & $4(7.3)$ & & $4(7.3)$ & $2(16.7)$ & $8(28.6)$ & \\
\hline Moderate $(101-400)$ & $13(26.5)$ & $6(10.9)$ & & $6(10.9)$ & $3(25)$ & $5(17.9)$ & \\
\hline Severe $(40 I-I, 000)$ & $8(16.3)$ & $0(0)$ & & $0(0)$ & I (8.3) & $4(14.3)$ & \\
\hline Very severe $(>1,000)$ & $2(4 . I)$ & $0(0)$ & & $0(0)$ & $0(0)$ & $2(7.1)$ & \\
\hline Percentile, n (\%) & & & $<0.0001$ & & & & $<0.0001$ \\
\hline No calcification (0) & II (22.4) & 39 (70.9) & & 39 (70.9) & $4(33.3)$ & $7(25)$ & \\
\hline Minimum (0-25) & I (2) & I (I.8) & & I (I.8) & I (8.3) & $0(0)$ & \\
\hline Mild (26-50) & $0(0)$ & $3(5.5)$ & & $3(5.5)$ & $0(0)$ & $0(0)$ & \\
\hline Moderate (5I-75) & $6(12.2)$ & $3(5.5)$ & & $3(5.5)$ & I (8.3) & $2(7.1)$ & \\
\hline Severe $(76-90)$ & $15(30.6)$ & $6(10.9)$ & & $6(10.9)$ & $2(16.7)$ & $9(32.1)$ & \\
\hline Very severe $(>90)$ & $16(32.7)$ & $3(5.5)$ & & $3(5.5)$ & $4(33.3)$ & $10(35.7)$ & \\
\hline
\end{tabular}

Notes: aP-value referring to the comparison of the GOLD stage groups with the non-COPD group. Other variables: chi-square or Fisher's exact test. Abbreviations: CACS, Agatston coronary artery calcium score; GOLD, Global Initiative for Obstructive Lung Disease. 
Table 4 Univariate and multivariate logistic regression with parameters associated with the presence of CAD

\begin{tabular}{|c|c|c|c|c|}
\hline \multirow[t]{2}{*}{ Parameter } & \multicolumn{2}{|c|}{ Univariate analysis } & \multicolumn{2}{|c|}{ Multivariate analysis } \\
\hline & OR (95\% CI) & $P$-value & OR (95\% Cl) & $P$-value \\
\hline COPD & $9.08(4.46-18.49)$ & $<0.001$ & I I.42 (5.30-24.59) & $<0.001$ \\
\hline Male & $2.76(1.53-4.97)$ & 0.001 & $3.96(1.96-7.98)$ & 0.001 \\
\hline Age & $1.05(1.02-1.08)$ & 0.002 & I.03 (0.99-I.07) & 0.07 \\
\hline Hypertension & $2.06(1.04-4.05)$ & 0.037 & $2.18(0.99-4.83)$ & 0.54 \\
\hline $\begin{array}{l}\text { Diabetes } \\
\text { mellitus }\end{array}$ & $1.74(0.93-3.25)$ & 0.083 & $1.65(0.77-3.54)$ & 0.20 \\
\hline Dyslipidemia & $1.47(0.80-2.68)$ & 0.21 & I. $19(0.55-2.55)$ & 0.65 \\
\hline Family history & $|.4|(0.77-2.55)$ & 0.26 & $1.42(0.65-3.07)$ & 0.37 \\
\hline
\end{tabular}

Note: This model was adjusted.

Abbreviations: $\mathrm{CAD}$, coronary artery disease; $\mathrm{Cl}$, confidence interval; $\mathrm{OR}$, odds ratio.

of obstructive and severe atherosclerotic lesions, a greater number of affected arteries, and greater coronary artery calcification. In addition, the association between the GOLD stages with the severity of CAD and with coronary calcification was evident.

A study indicates that in patients with established $\mathrm{CAD}, \mathrm{AL}$ is underdiagnosed, with reported occurrences in $10 \%-14 \%$ of individuals older than 40 years. ${ }^{25}$ The patients included in this study had never been evaluated for COPD, which suggests underdiagnosis of this condition in patients with suspected CAD. The diagnosis of COPD is often neglected, especially in the early stages of the disease. This stems from the fact that the signs and symptoms of lung injury in patients with mild chronic bronchitis and emphysema are often attributed to smoking ${ }^{26}$ or heart disease. Therefore, by knowing that COPD is preventable and treatable, its early detection could lead to therapeutic interventions that could improve the prognosis of these patients. ${ }^{14}$ In addition, being aware of the disease and the consequent potential risk determine the adoption of measures aimed at cessation of smoking, optimizing therapy with the goal of preventing pathological progression, ${ }^{27}$ focusing on the reduction of exacerbations, loss of flow, and functional deterioration of COPD. ${ }^{28}$

Table 5 Multivariate logistic regression with parameters associated with obstructive CAD (atherosclerotic lesion $\geq 50 \%$ )

\begin{tabular}{llll}
\hline Parameter & OR & $95 \% \mathbf{C l}$ & $P$-value \\
\hline COPD & 4.78 & $2.21-10.34$ & $<0.001$ \\
Male & 1.55 & $0.66-3.65$ & 0.31 \\
Age & 1.04 & $0.99-1.09$ & 0.07 \\
Hypertension & 0.40 & $0.12-1.29$ & 0.13 \\
Dyslipidemia & 1.80 & $0.78-4.14$ & 0.16 \\
\hline
\end{tabular}

Note: This model was adjusted.

Abbreviations: $\mathrm{CAD}$, coronary artery disease; $\mathrm{Cl}$, confidence interval; OR, odds ratio.
In this study, $88.1 \%$ of the patients had coronary lesions (CAD), and $71.3 \%$ of obstructive coronary lesions ( $\geq 50 \%$ of the vessel) occurred in patients with COPD. The prevalence of proven $\mathrm{CAD}$ in patients with COPD is known and ranges from $47 \%$ to $60 \%$. $^{7}$ However, in patients with undiagnosed COPD, this prevalence is poorly described in the literature, especially in relation to suspected CAD. And since there were no patients with active COPD exacerbations included in the study sample, the high frequency of CAD and obstructive lesions reinforces the hypothesis of association between these comorbidities.

Barnes $^{29}$ suggested that long-term memory $\mathrm{T}$ cells, bacterial colonization, or autoimmunity can lead to persistent inflammatory processes in ex-smokers with AL. Thus, the systemic inflammation that occurs with COPD may influence the frequency, severity, and extent of coronary lesions even in the initial stages of the process.

However, Enriquez et al $^{13}$ reported that COPD predisposes to a phenotype of diffuse atherosclerosis and multiarterial lesions, but with a lower tendency to develop occlusion of the vessel. In this study, COPD patients predominantly had multivessel CAD, with more lesions of the left coronary trunk, large occlusions, and a greater number of calcified coronary plaques. The use of spirometry, $\mathrm{CAG}$, and MDCT to confirm the diagnosis of COPD and CAD may have helped to produce this difference because in the aforementioned study the patients were recruited by telephone recordings.

The frequent occurrence of stenosis, severe lesions, and markedly calcified coronary plaques, especially in the GOLD III group (even with the small sample), was another finding of this study and reinforces the conclusion that the inflammatory processes of COPD do not participate only in the formation of atherosclerotic plaques but also in their progression. ${ }^{30-32}$

Williams et $\mathrm{al}^{8}$ found a higher CACS in COPD patients and associated dyspnea and reduced exercise capacity, data coincident with our study where patients with undiagnosed COPD had higher and more frequent CACS, dyspnea, and lower functional capacity (evaluated by $\mathrm{mMRC}$ score). In addition, as coronary calcification is a marker of subclinical atherosclerosis and suggests a higher risk for $\mathrm{CAD},{ }^{29}$ the frequency of moderate to very severe CAD in the GOLD I and II stages reinforces the hypothesis that even in COPD patients with undiagnosed disease, CAD can be significant.

Hypertension, DM, dyslipidemia, and sedentary lifestyle have been considered to be factors that influence the prognosis of COPD,${ }^{14,32}$ but in the present study there was no difference for these factors between the groups with and without this 
disease; and despite being considered the main risk factors for atherosclerosis, ${ }^{33}$ there was no association between the aforementioned factors and the presence of total coronary lesions or the obstructive lesions. De Lucas-Ramos et $\mathrm{al}^{11}$ found in a multicenter case-control study that COPD was an independent predictor of CAD and considered these same pathologies and health indicators. Because these factors are involved in atherogenesis and adversely affect the prognosis of CAD, systemic inflammation in COPD patients may accelerate atherogenesis independently of these risk factors or the lipid profile. Therefore, compromised lung function has associations with CAD independent of the effects of smoking in patients with normal total cholesterol and low levels of low-density lipoprotein. ${ }^{34}$ COPD patients from this research were more exposed to tobacco, but the relationship between COPD and CAD was found even in ex-smokers, since after COPD develops, cessation of smoking may not completely attenuate the inflammatory process. ${ }^{34}$ According to Zhang et al, ${ }^{35}$ inflammatory changes in lung vessel structure and function result in increased arterial stiffness independent of exposure to cigarette smoke.

Logistic regression analysis indicated that COPD was predictive of CAD $(P<0.001)$ and was an independent predictor of obstructive lesions $>50 \%$ of the coronary lumen $(P<0.001)$. Izquierdo et $\mathrm{al}^{12}$ performed spirometry in stable patients with a history of ACS and found no association between COPD and ischemic heart disease, including an adjusted analysis (OR 1.14, 95\% CI: 0.57-2.29). In contrast, Dursunoglu et $\mathrm{al}^{10}$ concluded that there was an increase in the extent and severity of CAD in patients with COPD compared to individuals without lung disease, and the presence of COPD was independently predictive of obstructive CAD (OR 1.374, 95\% CI: 1.672-9.232, $P=0.001$ ). Thus, they found an OR three times lower than that of this study.

\section{Study limitations}

Findings of this study were limited by its cross-sectional nature, which made it difficult to follow-up patients. The patients were from two different centers, a private hospital that mostly performs CAG in supplementary health network users and a public hospital that performs MDCT in patients using the Unified National Health System, which indirectly contributes to a greater sample differentiation in relation to the target population.

\section{Conclusion}

In CAD patients suspected, COPD is associated with increased severity and extent of coronary lesions, calcific plaques, and elevated calcium scores, independent of the traditional risk factors for established CAD. The more advanced the COPD, the greater the coronary lesions and calcification. In addition, COPD is a predictor of the presence of CAD (total coronary lesions) and obstructive lesions blocking more than $50 \%$ of the coronary artery lumen.

\section{Disclosure}

The authors report no conflicts of interest in this work.

\section{References}

1. Diaz-Guzman E, Mannino DM. Epidemiology and prevalence of chronic obstructive pulmonary disease. Clin Chest Med. 2014;35(1):7-16.

2. World Health Organization [webpage on the Internet]. Cardiovascular Disease. 2016. [2016; cited 2016 Set]; Available from: http://www. who.int/cardiovascular_diseases/en/. Accessed June 2017.

3. Papaioannou AI, Bartziokas K, Loukides S, et al. Cardiovascular comorbidities in hospitalised COPD patients: a determinant of future risk? Eur Respir J. 2015;46(3):846-849.

4. Smith MC, Wrobel JP. Epidemiology and clinical impact of major comorbidities in patients with COPD. Int J Chron Obstruct Pulmon Dis. 2014;9:871-888.

5. Chen W, Thomas J, Sadatsafavi M, FitzGerald JM. Risk of cardiovascular comorbidity in patients with chronic obstructive pulmonary disease: a systematic review and meta-analysis. Lancet Respir Med. 2015;3(8):631-639.

6. Mannino DM, Higuchi K, Yu T-C, et al. Economic burden of chronic obstructive pulmonary disease by presence of comorbidities. Chest. 2014; 147:1199-1201.

7. Roversi S, Roversi P, Spadafora G, Rossi R, Fabbri LM. Coronary artery disease concomitant with chronic obstructive pulmonary disease. Eur J Clin Invest. 2014;44(1):93-102.

8. Williams MC, Murchison JT, Edwards LD, et al. Coronary artery calcification is increased in patients with COPD and associated with increased morbidity and mortality. Thorax. 2014;69(8):718-723.

9. Decramer M, Janssens W. Chronic obstructive pulmonary disease and comorbidities. Lancet Respir Med. 2013;1(1):73-83.

10. Dursunoglu N, Dursunoglu D, Yildiz AI, Uludag B, Alacam ZN, Saricopur A. Severity of coronary atherosclerosis in patients with COPD. Clin Respir J. 2016;11(6):751-756.

11. de Lucas-Ramos P, Izquierdo-Alonso JL, Moro JMR-G, et al. CONSISTE Study Group. Chronic obstructive pulmonary disease as a cardiovascular risk factor. Results of a case-control study (CONSISTE study). Int J Chron Obstruct Pulmon Dis. 2012;7:679-686.

12. Izquierdo JL, Martinez A, Guzman E, de Lucas P, Rodriguez JM. Lack of association of ischemic heart disease with COPD when taking into account classical cardiovascular risk factors. Int J Chron Obstruct Pulmon Dis. 2010;5:387-394.

13. Enriquez JR, Parikh SV, Selzer F, et al. Increased adverse events after percutaneous coronary intervention in patients with COPD: insights from the national heart, lung, and blood institute dynamic registry. Chest. 2011;140(3):604-610.

14. Vogelmeier CF, Criner GJ, Martinez FJ, et al. Global strategy for the diagnosis, management, and prevention of chronic obstructive lung disease 2017 report. GOLD executive summary. Am J Respir Crit Care Med. 2017;195(5):557-582.

15. Xavier HT, Izar MC, Faria Neto JR, et al. V Diretriz Brasileira de Dislipidemias e Prevenção da Aterosclerose. Arq Bras Cardiol. 2013; 101(4 Suppl 1):1-20.

16. Mancia G, Fagard R, Narkiewicz K, et al. 2013 ESH/ESC guidelines for the management of arterial hypertension: the task force for the management of arterial hypertension of the European Society of Hypertension (ESH) and of the European Society of Cardiology (ESC). J Hypertens. 2013;31(7):1281-1357. 
17. Task Force on Diabetes, Pre-Diabetes, and Cardiovascular Diseases of the European Society of Cardiology (ESC), European Association for the Study of Diabetes (EASD), Ryden L, et al. ESC guidelines on diabetes, pre-diabetes, and cardiovascular diseases developed in collaboration with the EASD - summary the task force on diabetes, pre-diabetes, and cardiovascular diseases of the European Society of Cardiology (ESC) and developed in col. Diab Vasc Dis Res. 2014;11(3):133-173.

18. Miller MR, Hankinson J, Brusasco V, et al. Standardisation of spirometry. Eur Respir J. 2005;26(2):319-338.

19. Pereira CADC. Espirometria. J Bras Pneumol. 2002;28(Suppl 3): $\mathrm{S} 1-\mathrm{S} 82$.

20. Hoel B, Eie H, Semb G, Sivertssen E. Selective coronary arteriography. Acta Med Scand. 1975;197(1-6):377-382.

21. Scanlon PJ, Faxon DP, Audet A, et al. ACC/AHA practice guidelines ACC/AHA guidelines for coronary angiography. J Am Coll Cardiol. 1999;33(6):1756-1824.

22. Agatston AS, Janowitz WR, Hildner FJ, Zusmer NR, Viamonte M Jr, Detrano R. Quantification of coronary artery calcium using ultrafast computed tomography. J Am Coll Cardiol. 1990;15(4):827-832.

23. Sara L, Szarf G, Tachibana A, et al. II Diretriz De Ressonância Magnética E Tomografia Computadorizada Cardiovascular Da Sociedade Brasileira De Cardiologia E Do Colégio Brasileiro De Radiologia. Arq Bras Cardiol. 2014;103(6 Suppl 3):1-86.

24. Azevedo CF, Rochitte CE, Lima JAC. Coronary artery calcium score and coronary computed tomographic angiography for cardiovascular risk stratification. Arq Bras Cardiol. 2012;98(6):559-568.

25. Ko FWS, Yan BP, Lam Y, Chu JHY, Chan K-P, Hui DSC. Undiagnosed airflow limitation is common in patients with coronary artery disease and associated with cardiac stress. Respirology. 2016;21(1):137-142.
26. Vestbo J, Lange P. Can GOLD stage 0 provide information of prognostic value in chronic obstructive pulmonary disease? Am J Respir Crit Care Med. 2002;166(3):329-332.

27. Kart L, Akkoyunlu ME, Bayram M, et al. COPD: an underdiagnosed disease at hospital environment. Wien Klin Wochenschr. 2014; 126(3-4):73-78.

28. Duffy S, Marron R, Voelker H, et al. Effect of beta-blockers on exacerbation rate and lung function in chronic obstructive pulmonary disease (COPD). Respir Res. 2017;18(1):124.

29. Barnes PJ. Inflammatory mechanisms in patients with chronic obstructive pulmonary disease. J Allergy Clin Immunol. 2016;138(1):16-27.

30. Pizarro C, Linnhoff F, van Essen F, et al. Lower extremity and carotid artery disease in COPD. ERJ open Res. 2016;2(4):00037-02016.

31. Bhatt SP, Dransfield MT. Chronic obstructive pulmonary disease and cardiovascular disease. Transl Res. 2013;162(4):237-251.

32. Baty F, Putora PM, Isenring B, Blum T, Brutsche M. Comorbidities and burden of COPD: a population based case-control study. PLoS One. 2013;8(5):e63285.

33. Mack M, Gopal A. Epidemiology, traditional and novel risk factors in coronary artery disease. Cardiol Clin. 2014;32(3):323-332.

34. Hasan A, Ansari N, Parvez A, Beg M, Bhargava R. Understanding the relation between COPD and coronary artery disease. J Indian Acad Clin Med. 2014;15(2):120-124.

35. Zhang M, Cheng Y-J, Zheng W, et al. Impact of chronic obstructive pulmonary disease on long-term outcome in patients with coronary artery disease undergoing percutaneous coronary intervention. Biomed Res Int. 2016;2016:8212459.
International Journal of COPD

\section{Publish your work in this journal}

The International Journal of COPD is an international, peer-reviewed journal of therapeutics and pharmacology focusing on concise rapid reporting of clinical studies and reviews in COPD. Special focus is given to the pathophysiological processes underlying the disease, intervention programs, patient focused education, and self management protocols.

\section{Dovepress}

This journal is indexed on PubMed Central, MedLine and CAS. The manuscript management system is completely online and includes a very quick and fair peer-review system, which is all easy to use. Visit http://www.dovepress.com/testimonials.php to read real quotes from published authors. 